\title{
Do common genetic variants in endotoxin signaling pathway contribute to predisposition to alcoholic liver cirrhosis?
}

\author{
Jan Petrášek ${ }^{1, a, *}$, Jaroslav A. Hubáček ${ }^{1}$, Felix \\ Stickel $^{2}$, Jan Šperl ${ }^{1}$, Thomas Berg ${ }^{3}$, Esther \\ Ruf $^{4}$, H.-Erich Wichmann ${ }^{4,5}$, Arne Pfeufer ${ }^{6,7}$, \\ Thomas Meitinger ${ }^{6,7}$, Pavel Trunečka ${ }^{1}$, Julius \\ Špičák ${ }^{1}$ and Milan Jirsa ${ }^{1}$ \\ ${ }^{1}$ Institute for Clinical and Experimental Medicine, \\ Prague, Czech Republic \\ ${ }^{2}$ Institute of Clinical Pharmacology, Inselspital Bern, \\ University of Bern, Switzerland \\ ${ }^{3}$ Department of Medicine, Charité - Campus \\ Virchow, Humboldt University Berlin, Berlin, \\ Germany \\ ${ }^{4}$ Helmholtz Center Munich, Munich, Germany \\ ${ }^{5}$ LMU-IBE Chair of Epidemiology, Munich, Germany \\ ${ }^{6}$ Helmholtz Center Munich, Munich, Germany \\ ${ }^{7}$ Technical University, Institute of Human Genetics, \\ Munich, Germany
}

\begin{abstract}
Background: Tumor necrosis factor- $\alpha$ (TNF- $\alpha$ ) and interleukin-1 $\beta$ (IL-1 $\beta$ ), produced by endotoxin-activated Kupffer cells, play a key role in the pathogenesis of alcoholic liver cirrhosis (ALC). Alleles TNFA -238A, $I L 1 B-31 T$ and variant IL $1 R N^{*} 2$ of repeat polymorphism in the gene encoding the IL-1 receptor antagonist increase production of TNF- $\alpha$ and IL-1 $\beta$, respectively. Alleles CD14 -159T, TLR4 c.896G and TLR4 c.1196T modify activation of Kupffer cells by endotoxin. We confirmed the published associations between these common variants and genetic predisposition to ALC by means of a large case-control association study conducted on two Central European populations.
\end{abstract}

Methods: The study population comprised a Czech sample of 198 ALC patients and 370 controls (MONICA project), and a German sample of 173 ALC patients and 331 controls (KORA-Augsburg), and 109 heavy drinkers without liver disease.

Results: Single locus analysis revealed no significant difference between patients and controls in all tested loci. Diplotype [IL1RN*2/*2; IL1B-31T+] was associated with increased risk of ALC in the pilot study, but not in the validation samples.

Conclusions: Although cytokine mediated immune reactions play a role in the pathogenesis of ALC,

${ }^{a}$ Current address: Department of Medicine, University of Massachusetts, Medical School, Worcester, MA, USA

*Corresponding author: Jan Petrášek, MD, Laboratory of Experimental Hepatology, Institute for Clinical and Experimental Medicine, Vídeňská 1958, 14021, Praha 4, Czech Republic

Phone: + 420261362773, Fax: +420241721666,

E-mail: jan.petrasek@ikem.cz

Received November 21, 2008; accepted January 20, 2009; previously published online March 12, 2009 hereditary susceptibility caused by variants in the corresponding genes is low in Central European populations.

Clin Chem Lab Med 2009;47:398-404.

Keywords: alcoholic; genetic; interleukin-1 $\beta$; liver cirrhosis; polymorphism; tumor necrosis factor- $\alpha$.

\section{Introduction}

Recent studies on epidemiology of alcoholic liver disease suggest that only $40 \%$ of heavy drinkers will develop steatohepatitis and less than $5 \%$ will develop cirrhosis $(1,2)$. In addition to the cumulative dose of alcohol, gender and certain comorbidities including viral hepatitis and obesity, and yet unidentified genetic factors account for at least $50 \%$ of the individual susceptibility to alcoholic liver cirrhosis (ALC) $(3,4)$. Numerous studies have focused on genetic variability of the genes encoding ethanol metabolizing enzymes, genes affecting the severity of liver steatosis, oxidative stress and fibrosis, as well as genes modifying the response to endotoxins (lipopolysaccharide, LPS) $(3,5)$. However, the results of candidate gene casecontrol studies have been either inconclusive or nonreplicable $(6,7)$.

The importance of endotoxins and activation of Kupffer cells in the pathogenesis of ALC is evidenced by experimental studies in animals (8-10) and humans $(10,11)$. Adachi et al. $(12,13)$ showed that Kupffer cell inactivation by gadolinium chloride, intestinal sterilization and targeted disruption of the genes encoding the LPS recognition receptor CD14 and the toll-like receptor 4 (TLR4) protected the animals from alcohol induced liver injury $(14,15)$. Similarly, mice knocked-out for tumor necrosis factor- $\alpha$ (TnfA) (16), type I-TnfA receptor (17), or interleukin-1 $\beta$ (IL-1B) (18) were resistant to alcohol-induced liver damage, whereas interleukin-1 receptor antagonist (IL1-ra) knockout mice were more susceptible to alcoholderived insults than their wildtype littermates (19). These data strongly support the crucial role of LPS receptors and the main inflammatory cytokines produced by Kupffer cells in mouse models of alcohol induced injury.

Several functionally relevant genetic variants have been identified in the genes for CD14, TLR4, tumor necrosis factor $\alpha$ (TNF- $\alpha$ ), IL-1 $\beta$ and IL-1ra in humans. Accordingly, the $-159 \mathrm{C} / \mathrm{T}$ variation in the promoter of CD14 enhances production of CD14 by monocytes (20), whereas two linked variations, c.896A/G and c. $1196 \mathrm{C} / \mathrm{T}$, in the coding region of TLR4 impede the activation of monocytes by LPS (21). The polymorphism $-238 \mathrm{G} / \mathrm{A}$ of the TNFA promoter increases the 
transcription of TNF- $\alpha$ (22). The IL 1 gene cluster on chromosome 2 contains $I L 1 B$ and IL $1 R N$ genes, which encode IL-1 $\beta$ and its receptor antagonist IL-1ra, respectively (23). The variant $-31 \mathrm{~T}$ in the promoter of $I L 1 B$, which changes the wildtype sequence -31CATAA to -31TATAA, significantly increases IL-1 transcription (24). The ILIRN gene contains a pentaallelic 86 -bp tandem repeat. The second most common $I L 1 R N^{*} 2$ allele containing two repeats increases the secretion rate of IL-1 $\beta$ in vitro (25). The role of these variations in susceptibility to alcohol-induced liver injury has been suggested by several groups (26-30), with the highest disease risk attributed to the IL-1 gene cluster polymorphisms in the Asian population $(27,28)$.

In our study, we sought to confirm the published associations between these common variations and genetic predisposition to ALC by means of a large case-control association study conducted on a Central European (CEU) population.

\section{Materials and methods}

\section{Subjects}

Primary assessment of allelic frequencies was performed in a pilot study. Positive associations were confirmed in validation samples. The study was approved by the institutional Review Boards of all participating centers. Written informed consent was obtained from all subjects and the study conformed to the declaration of Helsinki Ethical Guidelines.

Pilot study We consecutively included 100 Caucasian patients with ALC referred to the Institute for Clinical and Experimental Medicine, Prague, Czech Republic, from March 2004 to October 2005. Their daily alcohol consumption was more than $40 \mathrm{~g}$ in female patients and more than $60 \mathrm{~g}$ in male patients for more than 10 years. The Czech control group consisted of 180 healthy volunteers without selfreported history of liver disease. The controls were selected out of 653 individuals after being ranked by a questionnaire on reported alcohol consumption, who participated in the population-based MONICA (MONItoring of trends and determinants in CArdiovascular disease) project between March 1996 and November 1997 (31).

Validation study For validation purposes, 173 patients with ALC treated in the Department of Medicine, University of Erlangen, Germany, and the Department of Medicine, Charité, Humboldt University Berlin, Germany, were analyzed. These patients had been recruited between August 1995 and December 2003. Their daily alcohol consumption was the same as for the Czech subjects. The German control group consisted of 331 healthy volunteers without self-reported history of liver disease. The controls were selected out of 812 individuals drinking $20-40 \mathrm{~g}$ of ethanol/day who were part of a total number of 4261 participants of the S4 survey of the population-based KORA (KOoperative Gesundheitsforschung in der Region Augsburg) project between 1999 and 2001 (32). In addition, a second German control group consisting of 109 heavy drinkers without liver disease was included. These patients were admitted between January 1999 and December 2003 to the University of Erlangen, Germany for alcohol detoxification or for other health-related problems, such as infections and accident injuries.
Subjects were assigned to the groups of ALC according to clinical/laboratory evidence for the presence of cirrhosis evidenced by simultaneous presence of: a) clinical findings typical for liver cirrhosis (jaundice, spider naevi, ascites, encephalopathy), b) abnormal blood tests (abnormal coagulation tests, decreased serum albumin concentration and platelet count), c) abnormal liver ultrasound, and d) esophageal varices on upper gastrointestinal endoscopy. In total, $11(5.6 \%)$ Czech and 22 (12.7\%) German patients with ALC who did not meet these criteria underwent liver biopsy due to presence of cirrhosis. Liver biopsy was not performed in patients with advanced liver dysfunction (coagulopathy and ascites) who met the above-mentioned criteria. A total of $83(42 \%)$ Czech and 96 (56\%) German patients with ALC underwent liver transplantation and the diagnosis of liver cirrhosis was confirmed in all cases by explanted liver histology. Patients with positive serology of hepatitis B or C, high ferritin and elevated transferrin saturation, anti-nuclear or anti-mitochondrial antibodies, decreased level of $\alpha_{1}$-antitrypsin and those with suspected liver cancer were excluded.

Heavy drinkers without liver cirrhosis had negative clinical findings indicating liver disease, normal blood tests and normal liver ultrasonography. Blood tests were performed while actively drinking and demonstrated normal results for alanine aminotransferase, aspartate aminotransferase, total bilirubin, albumin, platelet count and prothrombin time. Elevation of $\gamma$-glutamyltransferase was not an exclusion factor. None of the heavy drinkers underwent upper gastrointestinal endoscopy or liver biopsy due to ethical reasons.

The demographic and alcohol exposure data on all studied groups are summarized in Table 1.

\section{Genotyping}

Genomic DNA was isolated from peripheral blood from all patients using the OIAamp DNA Blood Mini Kit (Qiagen $\mathrm{GmbH}$, Hilden, Germany). For MONICA and KORA controls, isolated DNA was obtained. Single nucleotide polymorphisms were determined by polymerase chain reaction (PCR) followed by restriction fragment length (RFLP) analysis of the products. Genotyping of the ILIRN variable number of tandem repeats (VNTR) locus was performed by a PCRbased fragment length polymorphism method (see Table 2). Restriction endonucleases were purchased from Fermentas (Fermentas UAB, Vilnius, Lithuania). The PCR products of the ILIRN VNTR analysis were coded as follows: allele $1=4$ repeats (size 442 -bp), allele $2=2$ repeats $(270-b p)$, allele $3=5$ repeats (528-bp), allele $4=3$ repeats (356-bp), allele $5=6$ repeats $(614$-bp). The rare alleles 3,4 and 5 , constituting less than $5 \%$ of the $I L 1 R N$ allelic variants, were grouped in the statistical analysis.

Samples from cases and controls were included in each 96-sample batch analyzed. In order to minimize genotyping errors, blank control wells were left on the PCR plates and assays were wholly re-typed if the call rate was below $90 \%$. Three operators, unaware of the status of the samples, independently performed the genotype assignment. Out of 3762 genotyping analyses performed, approximately 100 (2.7\%) were duplicated due to the discrepancy between operators. After testing for Hardy-Weinberg equilibrium, allele frequencies were checked for consistency with data from the population of European ancestry [Utah Residents with Northern and Western European Ancestry (CEU)] from the HapMap database (33).

\section{Statistical analysis}

Two-sided power calculations at $p=0.05$ for $80 \%$ statistical power were performed using the DSTPLAN software (http:// 
Table 1 Demographic and alcohol exposure data on patients with ALC, general population controls without cirrhosis and heavy drinkers without cirrhosis.

\begin{tabular}{llcc}
\hline & $\begin{array}{l}\text { Alcoholic liver } \\
\text { cirrhosis }\end{array}$ & $\begin{array}{l}\text { Controls without } \\
\text { cirrhosis }\end{array}$ & $\begin{array}{l}\text { Heavy drinkers } \\
\text { without cirrhosis }\end{array}$ \\
\hline $\begin{array}{l}\text { Czech study population ( } \mathrm{n}=568) \\
\mathrm{n}\end{array}$ & 198 & 370 & - \\
Male (\%) & $149(75.3)$ & $255(69.0)$ & - \\
Age, years, median (IQR) & $54(26-72)^{\mathrm{a}}$ & $50(24-80)$ & - \\
Alcohol, g/day, median (range) & $100(75-143)^{\mathrm{a}}$ & $13(6-29)$ & 109 \\
German study population ( $\mathrm{n}=613)$ & 173 & 331 & $84(77.1)$ \\
$\mathrm{n}$ & $117(67.6)$ & $222(67.0)$ & $43(22-70)$ \\
Male (\%) & $50(24-71)^{\mathrm{b}}$ & $50(30-69)$ & $250(185-335)$ \\
Age, years, median (IQR) & $100(70-150)^{\mathrm{c}}$ & $30(20-40)$ & - \\
Alcohol, g/day, median (range) & & & \\
\hline
\end{tabular}

${ }^{a} p<0.05$ vs. controls without liver cirrhosis; ${ }^{b} p<0.05$ vs. heavy drinkers without cirrhosis; ${ }^{c} p<0.05$ vs. controls without liver cirrhosis and vs. heavy drinkers without cirrhosis. IQR, interquartile range.

Table 2 Genotyped loci in the CD14, TLR4, TNFA, IL1B and IL1RN genes.

\begin{tabular}{|c|c|c|c|}
\hline $\begin{array}{l}\text { Variation } \\
\text { Ref. dbSNPa id }\end{array}$ & $\begin{array}{l}\text { Forward primer } \\
\text { Reverse primer }\end{array}$ & $\begin{array}{l}\mathrm{T}_{\mathrm{m}},{ }^{\circ} \mathrm{C} \\
\text { Time, } \mathrm{s}\end{array}$ & $\begin{array}{l}\text { Restriction enzyme } \\
\text { Fragment length, bp }\end{array}$ \\
\hline CD14 -159C/T & 5'-TTGGTGCCAACAGATGAGGTTCAC-3' & $60^{\circ} \mathrm{C}$ & Haelll \\
\hline rs2569190 & 5'-TTCTTTCCTACACAGCGGCACCC-3' & $30 \mathrm{~s}$ & $204,201,156$ \\
\hline$T L R 4$ c.896A/G & 5'-GATTAGCATACTTAGACTACTACCTCCATG-3' & $59^{\circ} \mathrm{C}$ & Ncol \\
\hline rs4986790 & 5'-GATCAACTTCTGAAAAAGCATTCCCAC-3' & $40 \mathrm{~s}$ & 223,26 \\
\hline TLR4 c. $1196 \mathrm{C} / \mathrm{T}$ & 5'-GGTTGCTGTTCTCAAAGTGATTTTGGGAGAA-3' & $55^{\circ} \mathrm{C}$ & Hinfl \\
\hline rs4986791 & 5'-ACCTGAAGACTGGAGAGTGAGTTAAATGCT-3' & $40 \mathrm{~s}$ & 378,29 \\
\hline$T N F A-238 \mathrm{G} / \mathrm{A}$ & 5'-GCCCCTCCCAGTTCTAGTTC-3' & $62^{\circ} \mathrm{C}$ & BamHI \\
\hline rs361525 & 5'-СТСАСАСТССССАТССТCCCGGATC-3' & $30 \mathrm{~s}$ & 185,26 \\
\hline$I L 1 B-31 \mathrm{C} / \mathrm{T}$ & 5'-CCСTTCCATGAACCAGAGAA-3' & $60^{\circ} \mathrm{C}$ & Alul \\
\hline rs1143627 & 5'-GCTGAAGAGAATCCCAGAGC-3' & $30 \mathrm{~s}$ & $97,87,54$ \\
\hline$I L 1 B-511 \mathrm{~T} / \mathrm{C}$ & 5'-TGGCATTGATCTGGTTCATC-3' & $60^{\circ} \mathrm{C}$ & Aval \\
\hline rs16944 & 5'-GCCCTCCCTGTTCTGTATTGA-3' & $30 \mathrm{~s}$ & 190,60 \\
\hline ILIRN VNTR & 5'-CCCCTCAGCAACACTCC-3' & $64^{\circ} \mathrm{C}$ & - \\
\hline $156109^{\mathrm{b}}$ & 5'-GGTCAGAAGGGCAGAGA-3' & $30 \mathrm{~s}$ & $442,270,528,356,61$ \\
\hline
\end{tabular}

${ }^{a} \mathrm{NCBI}$ database of genetic variation, www.ncbi.nlm.nih.gov/SNP. 'bCBI database of unified sequence tagged sites, www.ncbi.nih.gov/genome/STS. VNTR, variable number of tandem repeats; $T_{m}$, melting temperature.

linkage.rockefeller.edu/soft). The size of the pilot study was calculated as follows. When the odds ratio (OR) of a polymorphism was assumed to be 2, the required sample size was 100 cases and 180 controls for the polymorphism with frequency of $0.5(C D 14-159 C / T)$. When the OR was assumed to be 4 , the same sample size was sufficient to detect a true effect of a polymorphism with frequency of 0.03 (TNFA $-238 \mathrm{G} / \mathrm{A})$. To confirm the association of the $\left[I L 1 R N^{*} 2{ }^{*} 2\right.$; ILIB $-31 T+]$ diplotype with ALC, we calculated the minimal size of the pilot and validation studies from the observed haplotype frequencies obtained by investigation of 100 Czech cases and 180 Czech controls and in the extended pilot study, respectively.

Hardy-Weinberg equilibrium of alleles at individual loci was evaluated using the program HWE (http://linkage. rockefeller.edu/soft). Haplotype frequencies for pairs of alleles were estimated using the software EH based on the expectation-maximization algorithm (http://linkage.rockefeller.edu/soft). Linkage disequilibrium (LD) coefficients $\mathrm{D}^{\prime}=\mathrm{D} / \mathrm{D}_{\text {min or max }}$ and $\mathrm{r}^{2}$ were calculated using the MIDAS software (34). Age and median alcohol consumption between the groups was compared using the Mann-Whitney test. Male to female ratios were compared using the Fisher exact test.

All association analyses were performed by logistic regression analysis using SPSS software version 14.0 (SPSS Inc., Chicago, IL, USA). Where applicable, logistic regression analysis adjusted for age was performed. Due to the multiple testing, the level of significance in the pilot study was set at $p<0.01$. In the extended pilot and validation studies, where only one association was tested, the level of significance was set at $p<0.05$. All $p$-values were two-sided.

\section{Results}

In the control populations, the alleles at the individual loci were in Hardy-Weinberg equilibrium. The genotype frequencies in healthy controls for all polymorphisms were in concordance with the reference HapMap database (33). As the LD between the IL1B -511 and $I L 1 B-31$ loci in 100 Czech patients with ALC and 180 population controls was perfect $\left(D^{\prime}=1, r^{2}=1\right)$, we investigated only the $I L 1 B-31$ polymorphism in both the pilot and validation samples. A significant $(p<0.0001)$ but weak LD $\left(D^{\prime}<0.5\right)$ was found between the $I L 1 B-31$ and $I L 1 R N$ VNTR loci.

\section{Single locus analysis}

Single locus analysis was performed in 100 Czech patients with ALC and 180 population controls (see Table 3). The proportion of the TLR4 c.1196T allele was higher in patients with ALC (8.5\%) than in healthy 
Table 3 Genotype frequencies in 100 Czech patients with ALC and 180 Czech healthy controls.

\begin{tabular}{|c|c|c|c|c|c|c|c|c|c|}
\hline \multirow[t]{3}{*}{ Locus } & \multirow[t]{3}{*}{ Genotype } & \multicolumn{2}{|c|}{ Patients } & \multicolumn{2}{|c|}{ Controls } & \multicolumn{4}{|c|}{ Association with alcoholic cirrhosis } \\
\hline & & \multirow[t]{2}{*}{$\mathrm{n}$} & \multirow[t]{2}{*}{$\%$} & \multirow[t]{2}{*}{$\mathrm{n}$} & \multirow[t]{2}{*}{$\%^{a}$} & \multicolumn{2}{|c|}{ Unadjusted } & \multicolumn{2}{|c|}{ Adjusted for age } \\
\hline & & & & & & $\mathrm{p}$ & OR $(95 \% \mathrm{Cl})$ & $\mathrm{p}$ & OR $(95 \% \mathrm{Cl})$ \\
\hline \multirow[t]{3}{*}{ CD14-159 } & $\mathrm{C} / \mathrm{C}$ & 21 & 21.0 & 31 & 17.2 & & 1 (reference) & & 1 (reference) \\
\hline & $\mathrm{C} / \mathrm{T}$ & 43 & 43.0 & 82 & 45.6 & 0.45 & $0.77(0.40-1.51)$ & 0.37 & $0.73(0.37-1.45)$ \\
\hline & $\mathrm{T} / \mathrm{T}$ & 36 & 36.0 & 67 & 37.2 & 0.51 & $0.79(0.40-1.58)$ & 0.49 & $0.78(0.36-1.58)$ \\
\hline \multirow[t]{3}{*}{ TLR4 c.896 } & $\mathrm{A} / \mathrm{A}$ & 85 & 85.0 & 160 & 88.8 & & 1 (reference) & & 1 (reference) \\
\hline & $A / G$ & 14 & 14.0 & 19 & 10.6 & 0.39 & $1.39(0.67-2.90)$ & 0.49 & $1.30(0.61-2.77)$ \\
\hline & $\mathrm{G} / \mathrm{G}$ & 1 & 1.0 & 1 & 0.6 & 0.66 & $1.88(0.12-30.5)$ & 0.72 & $1.67(0.10-27.2)$ \\
\hline \multirow[t]{3}{*}{ TLR4 c. 1196} & $\mathrm{C} / \mathrm{C}$ & 85 & 85.0 & 166 & 92.2 & & 1 (reference) & & 1 (reference) \\
\hline & $\mathrm{C} / \mathrm{T}$ & 13 & 13.0 & 13 & 7.2 & 0.11 & $1.95(0.87-4.40)$ & 0.13 & $1.91(0.83-4.37)$ \\
\hline & $\mathrm{T} / \mathrm{T}$ & 2 & 2.0 & 1 & 0.6 & 0.27 & $3.90(0.35-43.7)$ & 0.21 & $4.79(0.41-56.6)$ \\
\hline \multirow[t]{3}{*}{$T N F-238$} & $\mathrm{G} / \mathrm{G}$ & 91 & 91.0 & 170 & 94.4 & & 1 (reference) & & 1 (reference) \\
\hline & $\mathrm{G} / \mathrm{A}$ & 9 & 9.0 & 10 & 5.6 & 0.28 & $1.68(0.66-4.29)$ & 0.28 & $1.17(0.65-4.48)$ \\
\hline & $A / A$ & 0 & 0.0 & 0 & 0 & & & & \\
\hline \multirow[t]{3}{*}{$I L 1 B-511$} & $\mathrm{~T} / \mathrm{T}$ & 14 & 14.0 & 23 & 12.8 & & 1 (reference) & & 1 (reference) \\
\hline & $\mathrm{C} / \mathrm{T}$ & 45 & 45.0 & 82 & 45.6 & 0.83 & $0.92(0.43-1.96)$ & 0.98 & $1.01(0.47-2.19)$ \\
\hline & $\mathrm{C} / \mathrm{C}$ & 41 & 41.0 & 75 & 41.7 & 0.74 & $0.88(0.41-1.89)$ & 0.97 & $0.98(0.45-2.16)$ \\
\hline \multirow[t]{3}{*}{$I L 1 B-31$} & $\mathrm{C} / \mathrm{C}$ & 14 & 14.0 & 23 & 12.8 & & 1 (reference) & & 1 (reference) \\
\hline & $\mathrm{C} / \mathrm{T}$ & 45 & 45.0 & 82 & 45.6 & 0.83 & $0.92(0.43-1.96)$ & 0.98 & $1.01(0.47-2.19)$ \\
\hline & $\mathrm{T} / \mathrm{T}$ & 41 & 41.0 & 75 & 41.7 & 0.74 & $0.88(0.41-1.89)$ & 0.97 & $0.98(0.45-2.16)$ \\
\hline \multirow[t]{5}{*}{ IL $1 R N$} & $1 / 1$ & 42 & 42.0 & 82 & 45.6 & & 1 (reference) & & 1 (reference) \\
\hline & $1 / 2$ & 47 & 47.0 & 80 & 44.4 & 0.49 & $1.20(0.72-2.02)$ & 0.37 & $1.28(0.75-2.16)$ \\
\hline & $2 / 2$ & 10 & 10.0 & 11 & 6.4 & 0.21 & $1.82(0.71-4.63)$ & 0.16 & $1.99(0.77-5.18)$ \\
\hline & $1 / 3,4,5$ & 1 & 1.0 & 5 & 2.8 & 0.25 & $0.29(0.03-2.40)$ & 0.42 & $0.41(0.05-3.57)$ \\
\hline & $2 / 3$ & 0 & 0.0 & 2 & 1.1 & & & & \\
\hline
\end{tabular}

${ }^{a}$ The sum of the percentages may exceed $100 \%$ due to rounding. OR, odds ratio; Cl, confidence interval.

controls $(4.2 \%)$, but the association was not significant. For the other six loci, no significant differences in allele or genotype frequency between patients and controls were found (Table 3 ). In spite of a better goodness-of-fit of the regression model, adjustment for age did not significantly influence the results. Furthermore, genotyping of the TNFA $-238 \mathrm{~A}, I L 1 B-31 \mathrm{~T}$, CD14 -159T and TLR4 c.1196T loci in an extended sample of 198 Czech ALC patients and 370 Czech controls did not yield any significant association. Specifically, the TLR4 c.1196T locus was not associated with ALC both in the heterozygous model [OR 1.56, $95 \%$ confidence interval $(\mathrm{Cl}) 0.88,2.78, \mathrm{p}=0.13$ ] and in the homozygous model (OR $3.93,95 \% \mathrm{Cl} 0.35$, 43.65, $p=0.26$ ).

Haplotype analysis In the pilot study of 100 Czech patients with ALC and 180 population controls, the
[IL 1RN*2/*2; IL 1B -31T+] diplotype, determined by homozygosity for the ILIRN allele 2 and carriage of the $I L 1 B-31 T$ allele, was associated with an increased risk of ALC when compared to other diplotypes in the IL-1 gene cluster. In total, $9 \%$ of cases (compared to $1.1 \%$ of controls) revealed this diplotype, with an ageadjusted OR of 9.45 (95\% Cl 1.96, 45.7, $p=0.005)$ for ALC (see Table 4). Although the power of the haplotype analysis was $85 \%$, we were aware of the wide $\mathrm{Cl}$ for the OR. Therefore, we evaluated the association of the diplotype in three subsequent steps.

First, we expanded the sample size of Czech patients and controls. Assuming an OR of 5, a required sample size of 198 cases and 370 controls was used. In total, 98 consecutive patients with ALC from the same center prospectively recruited between November 2005 and September 2006 were added to the 100 Czech patients included in the pilot study, and

Table 4 Association of the $\left[I L 1 R N^{*} 2 /{ }^{*} 2 ; I L 1 B-31 T+\right]$ diplotype with ALC in patients with ALC, healthy population controls and heavy drinkers without cirrhosis.

\begin{tabular}{|c|c|c|c|c|}
\hline \multirow[t]{2}{*}{ Population } & \multicolumn{2}{|c|}{ Unadjusted } & \multicolumn{2}{|c|}{ Adjusted for age } \\
\hline & $\mathrm{p}$ & OR $(95 \% \mathrm{Cl})$ & $\mathrm{p}$ & OR $(95 \% \mathrm{Cl})$ \\
\hline $\begin{array}{l}\text { Pilot study ( } 100 \text { Czech ALC patients vs. } 180 \\
\text { Czech population controls) }\end{array}$ & 0.006 & $8.80(1.86-41.6)$ & 0.005 & $9.45(1.96-45.7)$ \\
\hline $\begin{array}{l}\text { Extended pilot study ( } 198 \text { Czech ALC } \\
\text { patients vs. } 370 \text { Czech population controls) }\end{array}$ & 0.083 & $2.09(0.97-4.84)$ & 0.092 & $2.06(0.89-4.78)$ \\
\hline $\begin{array}{l}\text { Validation I ( } 173 \text { German ALC patients vs. } \\
331 \text { German population controls) }\end{array}$ & 0.973 & $0.99(0.52-1.90)$ & a & a \\
\hline $\begin{array}{l}\text { Validation II ( } 173 \text { German ALC patients vs. } \\
109 \text { German heavy drinkers without ALC) }\end{array}$ & 0.326 & $1.63(0.61-4.34)$ & 0.484 & $1.44(0.52-3.95)$ \\
\hline
\end{tabular}

${ }^{a}$ As there was no age difference between cases and controls, no adjustment for age was performed. OR, odds ratio; $\mathrm{Cl}$, confidence interval; ALC, alcoholic liver cirrhosis. 
the control sample was extended by 190 subjects from the MONICA study. Thus, the total population sample comprised 198 patients and 370 controls. The association of the $\left[I L 1 R N^{*} 2 / * 2 ; I L 1 B-31 T+\right]$ diplotype was not significant; however, it was close (age-adjusted OR 2.06, 95\% Cl 0.89, 4.78, $\mathrm{p}=0.09$ ). The non-significance could be caused by increased prevalence of the diplotype in the extended number of controls $(2.8 \%)$.

Second, the $\left[I L 1 R N^{*} 2{ }^{*} 2 ; I L 1 B-31 T+\right]$ diplotype frequency of German ALC patients was compared to that of the German population control group. Assuming an OR of 2.5, a required sample size of 173 cases and 331 controls was used in the validation study. No association with ALC due to the same prevalence of the diplotype in patients and controls $18.8 \%$ in both groups) was found.

Finally, the association was further tested in German patients with ALC and heavy drinkers without liver disease as controls. Even then, no significant association was found (see Table 4), and the frequency of the $\left[I L 1 R N^{*} 2 /^{*} 2 ; I L 1 B-31 T+\right]$ diplotype in the group of healthy heavy drinkers was not significantly different from that in German population controls $(5.5 \%$ vs. $8.8 \%, p=0.30)$.

\section{Discussion}

In our study, we included only those genes encoding cytokines whose role in ALC was proved in animal models and those polymorphisms whose impact on gene expression or protein function was described in in vitro studies. Moreover, the included polymorphisms have been associated with an increased risk of alcoholic liver disease $(26,29,30,35)$, accelerated progression of fibrosis in chronic hepatitis B (36) and endotoxin hyporesponsiveness in humans (21). To include gene variants with the largest possible effect size, we also investigated the $\left[I L 1 R N^{*} 2 /{ }^{*} 2 ; I L 1 B\right.$ $-31 \mathrm{~T}+$ ] diplotype, because it increases the production of IL-1 $\beta$ more than either of the polymorphisms alone $(24,25)$. This is enabled by the low strength of LD which permits the additive effect of both proinflammatory alleles (i.e., $I L 1 R N^{*} 2$ and $I L 1 B-31 T$ ) on IL-1 $\beta$ production. Importantly, both polymorphisms increased the risk of ALC in the Asian population with a high OR for the disease exceeding $4.5(27,28)$. Contrary to the paper by Takamatsu et al. (27), we did not include the $I L 1 B+3953 C / T$ polymorphism because it does not alter in vitro protein secretion (37), and we did not include the silent $I L 1 B-511 C$ allele. Instead, we analyzed the $I L 1 B-31 T$ allele, which is in complete LD with the $I L 1 B-511 C$ allele, creates a TATAA sequence in the promoter and results in a five-fold increase of IL $1 B$ transcription (24).

Selection of the appropriate cases and controls is a major issue in genetic studies on ALC. In case-control studies, individuals with the disease under investigation (cases) are compared to individuals who do not have the disease, but who are thought to be comparable in other respects (controls). Inclusion of patients with advanced ALC reduces the risk of misclassification, increases phenotypic homogeneity and the power to detect genetic association. Indeed, selection of extreme cases, such as patients undergoing liver transplantation, further increases the power of the study but also inflates the estimation of populationbased parameters, such as population attributable risk. However, it was not the purpose of our study to assess this measure because such assessment would require a significantly higher number of individuals with ALC recruited in a population-based manner.

Daly and Day (38) advocated that control individuals in genetic studies should reveal a comparable exposure to alcohol as cases. Compared to population controls, use of "hypernormal" controls (healthy heavy drinkers) would be expected to improve the power by increasing the difference in susceptibility allele frequency between cases and controls. However, this benefit is usually not substantial and is counterweighted by the costs and effort of defining a “hypernormal" population (39). In our study, investigating healthy German heavy drinkers did not yield a positive association with an increased risk of $A L C$ and the frequency of the $\left[I L 1 R N^{*} 2 /{ }^{*} 2 ; I L 1 B-31 T+\right]$ diplotype in this group was not significantly different from that in German population controls. Taken together, it does not seem to us that inclusion of "hypernormal" controls is superior to population controls.

The discrepancy between our findings and the previously published studies $(26-30,35,40)$ might be explained by ethnical differences and/or the lack of statistical power. Moreover, none of the studies $(26-30,35,40)$ included an independent validation sample which should be implemented particularly in smaller studies that are likely to be subject to a type 1 error which overestimates a genetic effect due to chance (41). Verifying positive findings in an independent validation sample helps to detect false associations, as exemplified in our study in which a seemingly positive association from a pilot study was rejected by its subsequent validation in an additional group of subjects with the same phenotype.

Also, genetic association studies are frequently subject to type 2 errors (false negativity), because polymorphisms are not causal and act only as phenotype modifiers. In our study, we maximized the power to detect an association with an increased risk of ALC by (i) selecting genes and polymorphisms that are expected to have the highest possible effect size (protection against alcohol-induced liver injury in animal knockout models, additive effect of $I L 1 B-31 T$ and

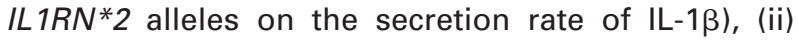
inclusion of patients with advanced ALC, and (iii) inclusion of "hypernormal" controls. The design of our study would enable us to detect biologically significant associations if they exist. Our study was not powered enough to detect OR below 2, although polymorphisms with a small effect size could act as disease modifiers and confer a measurable attributable risk. However, their clinical significance is questionable. In fact, they could hardly be used for predicting the risk of ALC in ethanol-drinking individuals, which 
is the ultimate goal of identifying disease susceptibility markers.

In conclusion, although there is little doubt that cytokine mediated immune reactions do play a role in the pathogenesis of ALC, hereditary susceptibility caused by variants in the corresponding genes seems to be low, or at least such is the case in a CEU population.

\section{Acknowledgements}

The study was supported by the Institute for Clinical and Experimental Medicine (MZO 00023001), Interdisciplinary Center for Clinical Research, University of Erlangen-Nuremberg, Germany (TP B39, to F.S.), and the KORA research platform, financed by the GSF-National Research Center for Environment and Health, funded by the German Federal Ministry of Education and Research and by the State of Bavaria. KORA-gen was supported partly by the German Ministry of Education and Research through the National Genome Research Network (NGFN). We thank L. Budišová, S. Režnáková and M. Zindr for technical assistance.

\section{References}

1. Bellentani S, Tiribelli $C$. The spectrum of liver disease in the general population: lesson from the Dionysos study. J Hepatol 2001;35:531-7.

2. Bellentani S, Saccoccio G, Costa G, Tiribelli C, Manenti F, Sodde M, et al. Drinking habits as cofactors of risk for alcohol induced liver damage. The Dionysos Study Group. Gut 1997;41:845-50.

3. Stickel $\mathrm{F}$, Osterreicher $\mathrm{CH}$. The role of genetic polymorphisms in alcoholic liver disease. Alcohol Alcohol 2006; 41:209-24.

4. Reed T, Page WF, Viken RJ, Christian JC. Genetic predisposition to organ-specific endpoints of alcoholism. Alcohol Clin Exp Res 1996; $20: \overline{1528-33 .}$

5. Day CP. Genes or environment to determine alcoholic liver disease and non-alcoholic fatty liver disease. Liver Int 2006;26:1021-8.

6. Zintzaras E, Stefanidis I, Santos M, Vidal F. Do alcoholmetabolizing enzyme gene polymorphisms increase the risk of alcoholism and alcoholic liver disease? Hepatology 2006;43:352-61.

7. Osterreicher $\mathrm{CH}$, Stickel F, Brenner DA. Genomics of liver fibrosis and cirrhosis. Semin Liver Dis 2007;27: 28-43.

8. Crews FT, Bechara R, Brown LA, Guidot DM, Mandrekar $\mathrm{P}, \mathrm{Oak} \mathrm{S}$, et al. Cytokines and alcohol. Alcohol Clin Exp Res 2006;30:720-30.

9. Reuben A. Alcohol and the liver. Curr Opin Gastroenterol 2007;23:283-91.

10. Mookerjee RP, Stadlbauer V, Lidder S, Wright GA, Hodges SJ, Davies NA, et al. Neutrophil dysfunction in alcoholic hepatitis superimposed on cirrhosis is reversible and predicts the outcome. Hepatology 2007;46:831-40.

11. Urbaschek R, McCuskey RS, Rudi V, Becker KP, Stickel $F$, Urbaschek B, et al. Endotoxin, endotoxin-neutralizingcapacity, sCD14, sICAM-1, and cytokines in patients with various degrees of alcoholic liver disease. Alcohol Clin Exp Res 2001;25:261-8.

12. Adachi Y, Bradford BU, Gao W, Bojes HK, Thurman RG. Inactivation of Kupffer cells prevents early alcoholinduced liver injury. Hepatology 1994;20:453-60.

13. Adachi Y, Moore LE, Bradford BU, Gao W, Thurman RG. Antibiotics prevent liver injury in rats following long-

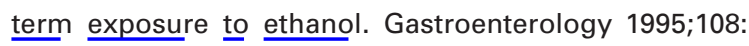
218-24.

14. Yin M, Bradford BU, Wheeler MD, Uesugi T, Froh M, Goyert SM, et al. Reduced early alcohol-induced liver injury in CD14-deficient mice. J Immunol 2001;166: 4737-42.

15. Uesugi T, Froh M, Arteel GE, Bradford BU, Thurman RG. Toll-like receptor 4 is involved in the mechanism of early alcohol-induced liver injury in mice. Hepatology 2001; 34:101-8.

16. Marino MW, Dunn A, Grail D, Inglese M, Noguchi $Y$, Richards $E$, et al. Characterization of tumor necrosis factor-deficient mice. Proc Natl Acad Sci USA 1997;94: 8093-8.

17. Yin M, Wheeler MD, Kono H, Bradford BU, Gallucci RM, Luster $\mathrm{MI}$, et al. Essential role of tumor necrosis factor alpha in alcohol-induced liver injury in mice. Gastroenterology 1999;117:942-52.

18. Fantuzzi $G$, Zheng $H$, Faggioni $R$, Benigni $F$, Ghezzi $P$, Sipe JD, et al. Effect of endotoxin in IL-1 beta-deficient mice. J Immunol 1996;157:291-6.

19. Hirsch E, Irikura VM, Paul SM, Hirsh D. Functions of interleukin 1 receptor antagonist in gene knockout and overproducing mice. Proc Natl Acad Sci USA 1996;93: 11008-13.

20. Hubacek JA, Rothe G, Pit'ha J, Skodova Z, Stanek V, Poledne R, et al. $\mathrm{C}(-260) \rightarrow T$ polymorphism in the promoter of the CD14 monocyte receptor gene as a risk factor for myocardial infarction. Circulation 1999;99: 3218-20.

21. Arbour NC, Lorenz E, Schutte BC, Zabner J, Kline JN, Jones $\mathrm{M}$, et al. TLR4 mutations are associated with endotoxin hyporesponsiveness in humans. Nat Genet 2000;25:187-91.

22. Bayley JP, de Rooij $H$, van den Elsen PJ, Huizinga TW, Verweij CL. Functional analysis of linker-scan mutants spanning the $-376,-308,-244$, and -238 polymorphic sites of the TNF-alpha promoter. Cytokine 2001;14:31623.

23. Dinarello CA. Biologic basis for interleukin-1 in disease. Blood 1996:87:2095-147.

24. El-Omar EM, Carrington M, Chow WH, McColl KE, Bream $\mathrm{JH}$, Young HA, et al. Interleukin-1 polymorphisms associated with increased risk of gastric cancer. Nature 2000; 404:398-402.

25. Santtila S, Savinainen K, Hurme M. Presence of the IL1RA allele 2 (IL $1 \mathrm{RN}^{*} 2$ ) is associated with enhanced IL1 beta production in vitro. Scand J Immunol 1998;47: 195-8.

26. Jarvelainen HA, Orpana A, Perola M, Savolainen VT, Karhunen PJ, Lindros KO. Promoter polymorphism of the CD14 endotoxin receptor gene as a risk factor for alcoholic liver disease. Hepatology 2001;33:1148-53.

27. Takamatsu M, Yamauchi M, Maezawa Y, Saito S, Maeyama S, Uchikoshi T. Genetic polymorphisms of interleukin-1beta in association with the development of alcoholic liver disease in Japanese patients. Am J Gastroenterol 2000;95:1305-11.

28. Chen WX, Xu GY, Yu CH, Wang P, Yu M, Xu P, et al. Correlation of polymorphism in the interleukin-1 receptor antagonist gene intron 2 with alcoholic liver disease. Hepatobil Pancreat Dis Int 2005;4:41-5.

29. Pastor IJ, Laso FJ, Romero A, Gonzalez-Sarmiento R. $-238 \mathrm{G}>$ A polymorphism of tumor necrosis factor alpha gene (TNFA) is associated with alcoholic liver cirrhosis in alcoholic Spanish men. Alcohol Clin Exp Res 2005; 29:1928-31.

30. Grove J, Daly AK, Bassendine MF, Day CP. Association of a tumor necrosis factor promoter polymorphism with susceptibility to alcoholic steatohepatitis. Hepatology 1997;26:143-6. 
31. Tunstall-Pedoe $H$, Kuulasmaa $K$, Tolonen $H$, Davidson $M$, Mendis S. In: Tunstall-Pedoe $\mathrm{H}$, editor. MONICA monograph and multimedia sourcebook. Geneva: World Health Organization, 2003.

32. Wichmann HE, Gieger C, Illig T. KORA-gen - resource for population genetics, controls and a broad spectrum of disease phenotypes. Gesundheitswesen 2005;67 (Suppl 1):S26-30.

33. Thorisson GA, Smith AV, Krishnan L, Stein LD. The international HapMap project web site. Genome Res 2005; 15:1592-3.

34. Gaunt TR, Rodriguez S, Zapata C, Day IN. MIDAS: software for analysis and visualisation of interallelic disequilibrium between multiallelic markers. BMC Bioinformatics 2006;7:227.

35. Campos J, Gonzalez-Quintela A, Quinteiro C, Gude F, Perez LF, Torre JA, et al. The $-159 \mathrm{C} / \mathrm{T}$ polymorphism in the promoter region of the CD14 gene is associated with advanced liver disease and higher serum levels of acutephase proteins in heavy drinkers. Alcohol Clin Exp Res 2005;29:1206-13.
36. Migita K, Maeda Y, Abiru S, Nakamura M, Komori A, Miyazoe $S$, et al. Polymorphisms of interleukin-1beta in Japanese patients with hepatitis B virus infection. J Hepatol 2007;46:381-6.

37. Dominici R, Malferrari G, Mariani C, Grimaldi L, Biunno I. The Interleukin 1-beta exonic $(+3953)$ polymorphism does not alter in vitro protein secretion. Exp Mol Pathol 2002;73:139-41.

38. Daly AK, Day CP. Candidate gene case-control association studies: advantages and potential pitfalls. $\mathrm{Br} \mathrm{J} \mathrm{Clin}$ Pharmacol 2001;52:489-99.

39. Hattersley AT, McCarthy MI. What makes a good genetic association study? Lancet 2005;366:1315-23.

40. Nguyen-Khac E, Houchi H, Daoust M, Dupas JL, Naassila M. The -308 TNFalpha gene polymorphism in severe acute alcoholic hepatitis: identification of a new susceptibility marker. Alcohol Clin Exp Res 2008;32:822-8.

41. Wacholder S, Chanock S, Garcia-Closas M, El Ghormli L, Rothman N. Assessing the probability that a positive report is false: an approach for molecular epidemiology studies. J Natl Cancer Inst 2004;96:434-42. 